\title{
Dear Sepp!
}

We miss your activity, your scientific leadership and your encouraging laughter.

Much has been said about your numerous merits, in the gratulations to your 75th and 80th birthday in Chironomus Newsletter ${ }^{1,2}$, in the celebration of the award of the Meigen-medal ${ }^{3}$, and on the occasion of your retirement as director of the $\mathrm{ZSM}^{4}$.

Only one honourable act is missing from these accounts: the opening of „Sammlung Fittkau“ 2011 in the Museum of Ethnology in Munich, a large collection of different South American artifacts of mainly Amazonas tribes, showing the outcome of your and your dear wife's friendship with those people. One newspaper declared the collection as „the second part of your scientific life“. I congratulated you at the time for stepping on the road to immortality. Well, you are still immortal in this sense.

I remember an early visit to Plön, where to a special room of family Fittkau the entrance for visitors was strongly forbidden, because of the danger that one would not return alive as a consequence of the many poisoned arrows etc. in the room.

We would not like to repeat all your merits here. But we thought that those who were closely connected with you, should report on their most memorable reminiscences of you, so to speak ,The best of Sepp“.

\section{Wolfgang Wülker:}

In 1968, you and I were together at the International Congress of Entomology in Moscow. Both of us were selected to take part in a post-congress excursion to Borok on the river Volga. Our Russian colleagues still acted with some reservation towards the ugly Germans in Moscow, but in Borok they were thawing remarkably and we had nice evenings with various local families. We both were directed to stay in a small house together with a nice young lady as our supervisor (most probably the daughter of a mighty Russian). In the beginning, she wanted to take a bath and was not sure whether or not this was ok in the presence of two wild Germans in the same house. I never forget you saying ,we are very shy persons“ - which indeed we were - and so the bathing could go on!

\section{Elisabeth Stur:}

Sepp became my 'Doktorvater' in 1993, right after he retired as director of the ZSM. He had been persuaded by Ulrike Nolte to take one 'last' PhD-student to work with chironomids in Brazil. - Well, as it turned out, I was not his last $\mathrm{PhD}$ student, - he could not say "no" to supervise the remaining "last students', my Brazilian friends and colleagues Angela, Sofia and Maria. Sepp and his beloved wife Elise has been part of my life since then, and I am very grateful for all their support.

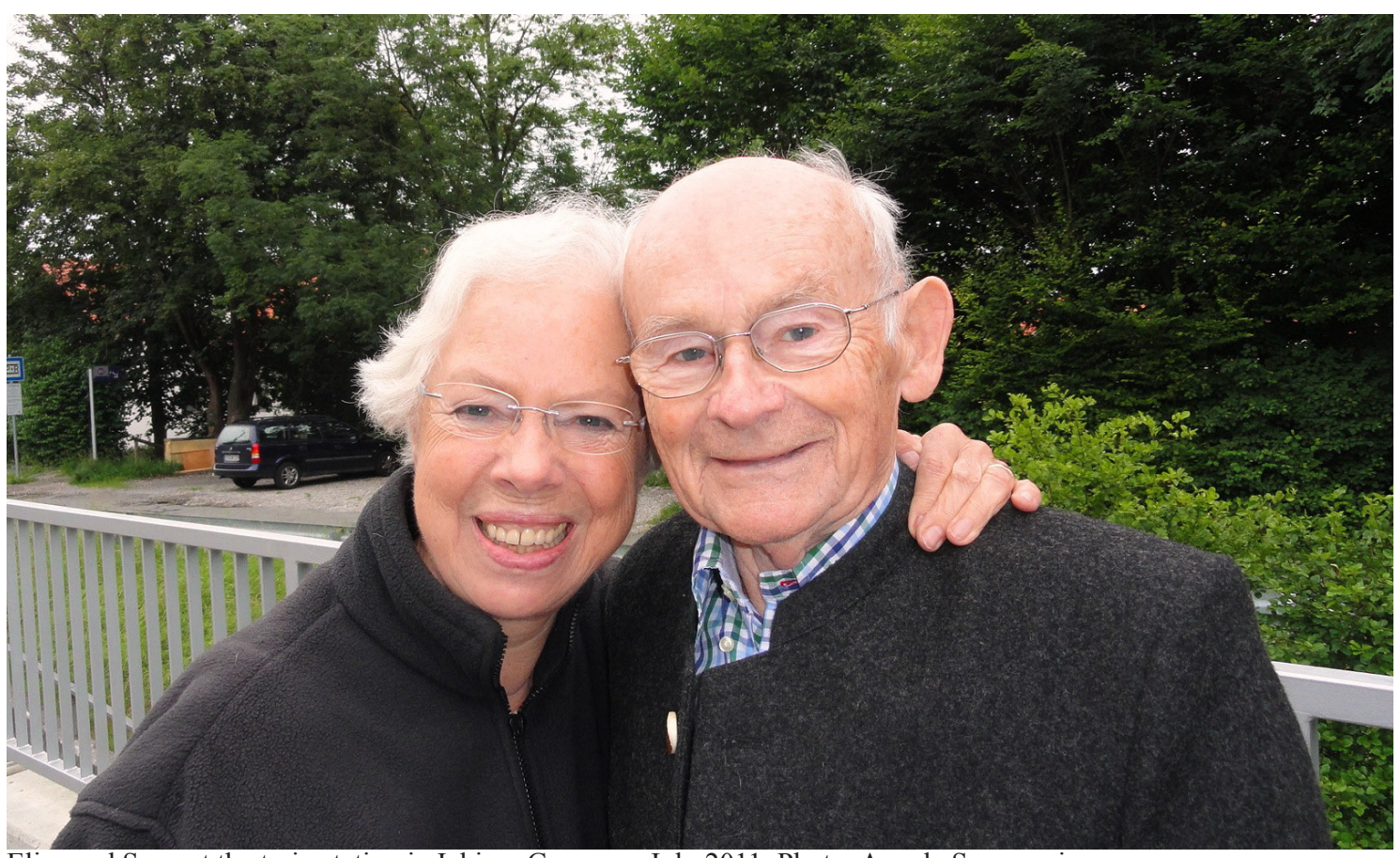

Elise and Sepp at the train station in Icking, Germany, July 2011. Photo: Angela Sanseverino. 


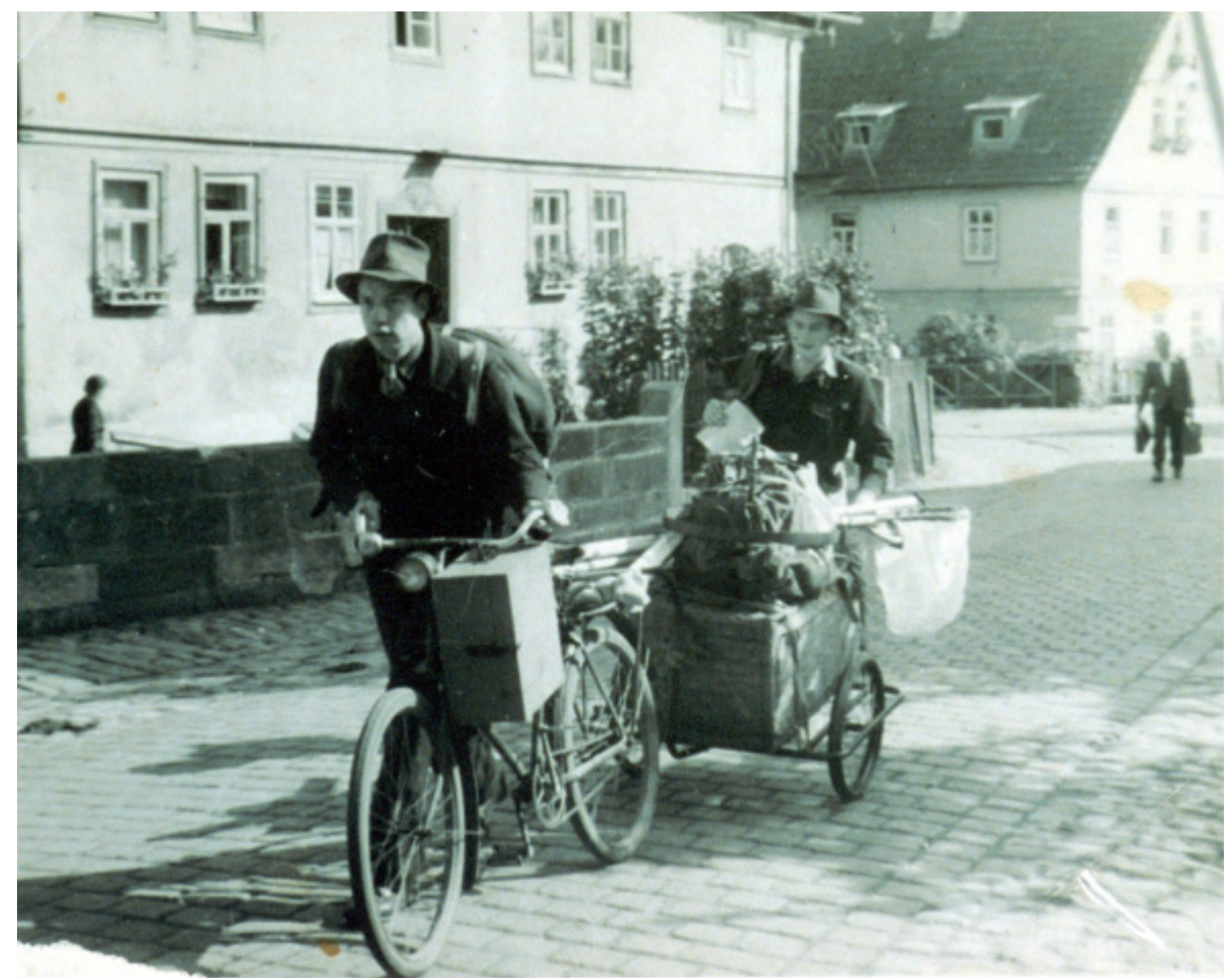

Joachim Illies and Ernst Josef Fittkau on their way to collect at the Wasserkuppe, 1948. Photo: Family archive.

I have many fond memories of Sepp. As supervisor he was very patient in explaining morphological structures and teaching how to draw, and he was always encouraging in the writing process. However, his care for students and colleagues beyond the professional activity was perhaps even more remarkable - no matter what background the person might have.

One memory I have is from a warm sunny February-day in Munich when I could convince him to leave the office for the benefit of some hours in the nearby Biergarten. It was such a fine day and we had a very joyful conversation of bygone days; including stories from his time with Thienemann, Brundin and many other chironomologists whom I only knew from literature. I still remember this day with affection.

\section{Angela Sanseverino:}

„The lines are too straight; your drawing needs more movement and life." It was a spring morning in 2000, and with those words Sepp introduced me the art of taxonomy. Immediately he took his pen and ink, and showed me how to give to a seta a simple and elegant movement. Sepp was always filling our lives with his enthusiasm and friendship. And of course, making us laugh with his brilliant stories, which are so well known by those who had the privilege to have been part of his life. I met Sepp for the first time in 1994, during the first Brazilian Chironomidae meeting. At that time I was a biology undergraduate student and after some minutes talking to him, I knew for sure that in the future I would like to do my doctoral dissertation under his supervision. It took five years more until I could finally be ready to start my $\mathrm{PhD}$ in Munich. Sepp generously accepted to supervise me, even though it would cost hours of his time, which he was aiming to spend entirely with his wife Elise and family after so many years dedicated to science and research. He was not only a supervisor, but a mentor and a dear friend who had always a kind word and smile and a house with opened doors to his students. Elise and Sepp have always welcomed me with open arms to their home. Like the warm welcome they gave me and my family last year in July, when we visited them in Icking after the Chironomid Symposium in Trondheim. We had a very nice conversation about family, friends, old stories and the future. On May 18, 2012 I came 
to Icking to say goodbye to Sepp. It was also a spring morning. We did not exchange words, it was not necessary. Some flies, bees and butterflies were flying around. A light wind blew making flowers and trees move exactly the way Sepp once intended to explain to me.

\section{Sofia Wiedenbrug:}

I was lucky to be Sepp's PhD student and there are many stories that I could tell. He impressed me quite a lot right from the beginning! I had brought many samples from Brazil to Germany, but in $\mathrm{Mu}-$ nich I realized that this material was insufficient to work on my PhD and I was so desolated about that! So, Sepp told me, he was invited to the "I Encontro Brasileiro sobre Chironomidae" in Rio and that I should attend this meeting, too. He offered himself to go with me to south Brazil in order to do some sampling after the Congress. At that time, I was not an experienced driver so he himself drove the car from Rio de Janeiro to Porto Alegre which, by the way, is a $1.500 \mathrm{~km}$ trip, teaching me all the way down to the south a lot about the fauna and flora of my own country. He was very pleasant company and a gentleman!

He is still present in my mind while I'm working, I can hear his comments about the drawings and the importance of being able to see and interpret difficult structures. I miss him as a teacher and I miss him as a friend. Thank you, Sepp.

\section{Maria C Messias:}

I was introduced to Sepp by my adviser Sebastião de Oliveira, in Instituto Oswaldo Cruz, Rio de Janeiro, 1995. Both had met after a period of 20 years, when Sepp and Oliveira celebrated this occasion for the peer-reviewing of my Ph.D. thesis proposal to Instituto Oswaldo Cruz and Zoologis-

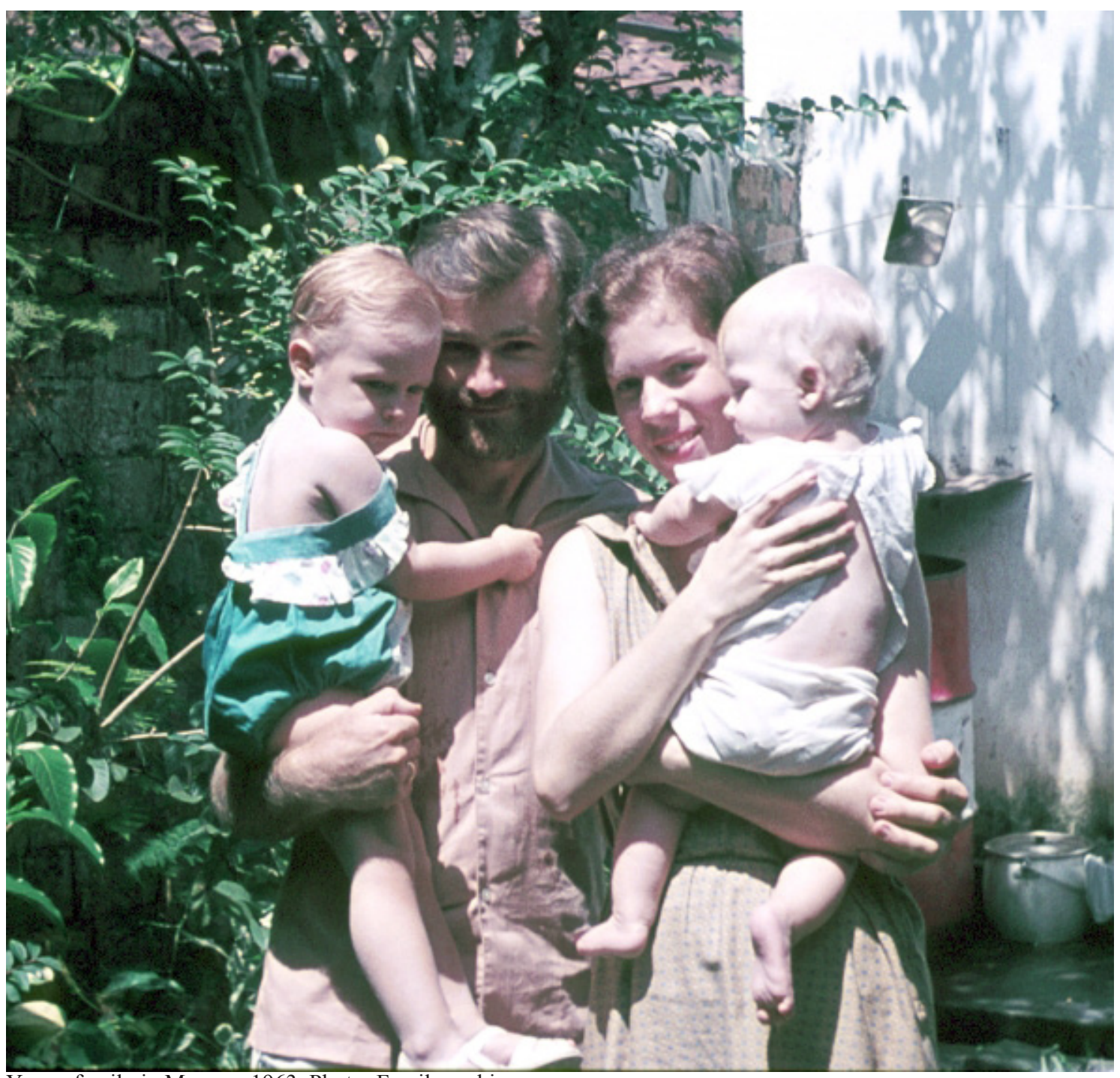

Young family in Manaus, 1963. Photo: Family archive. 
che Staatssammlung, Germany. Later, several times I heard Sepp encourage me to advance the research work telling me , go on, Maria, the work is going ok, a big master does not fall from heaven“. What I learned from him was not only on Chironomidae, but personal values such as happiness of living, to share and celebrate friendship. A master might not fall from heaven, but a master like Sepp stimulated us to grow with him, to dream and work hard, so that we can achieve our dreams, heaven and perfection.

\section{Martin Spies:}

In my early 1980s undergraduate years - long before I succumbed to the siren song of the midges (you never ordered or coaxed me into this group) - on the way to a field course you told me some things about your work on chironomids. Suddenly you burst into a desperate cry (like I never heard from you again): "That [personal name omitted here] is destroying my [taxon name omitted here] systematics!" In the years to follow, you proceeded to collaborate closely with that same person to produce several standard references for everyone studying the taxon in question. You tried hard not to let differences in professional opinion affect personal relations, and in the interests of the latter you were ready to make compromises in the former.

In your words of gratitude upon being awarded the Meigen medal', you wrote: "It has been a particularly important aim for me to coordinate chironomid research internationally and to provide training for junior colleagues." I feel fortunate to have watched you do both, and to be among those aware of the resulting benefits we keep enjoying. You have succeeded, Sepp, and - in contrast to some elbow societies in other disciplines - our community has been the better for that work of yours.

When someone approached you with an idea for something to study, you often responded with a broad smile and your jovial "Machen Sie mal!" (the closest translation, unfortunately, has become a copyrighted slogan for a global sportswear seller). I cannot thank you enough for all your optimistic encouragement, infinitely patient guidance, and unselfish help.

If there is any place where we may meet again, I'm positive that you'll receive us there with now eternal energy and enthusiasm, and share with us, immediately after our arrival, what you've discovered in this next new world of wonder.

\section{Roland Gerstmeier:}

In 1980 Sepp gave me the opportunity to prepare my doctoral thesis at the ZSM. I really appreciated the topic - especially when I was in a small boat on large Starnberger See, hauling an Ekman-Birge sampler with profundal benthos and substrate for up to $120 \mathrm{~m}$ from bottom to surface. Much deeper still, however, was my gratitude for the total freedom that Sepp offered me and all his students.

I greatly enjoyed coffee breaks at the museum with him and Frieder Reiss, when the two recounted their adventures in South America - stories about indigenous people in Amazonia, for example Sepp's affiliation with the Canela tribe, or about struggles with flight attendants when he brought whole spears, blowpipes or canoes into the cabin. One evening in a hotel room shared with Frieder, Sepp intentionally broke a giant traditional, old and precious clay pot. When Frieder cried out why he did this, Sepp's answer was: "How else should I bring this on the airplane? I can glue the pieces back together in Munich" (which he did). In 1983, at the age of 56, Sepp travelled to Peru with some considerably younger companions. After a 45-minute drive from Lima to the high Andes (4800 m), Sepp jumped out of the car and galloped across the slopes like a mountain goat, while his fellow travelers suffered from bad headache and lethargy.

Sepp has opened my way and my senses to many things - he will always be in my mind and in my heart.

\section{Claus Orendt:}

I remember Sepp as a master of ,very dry humour“ or stories, which seemed unbelieveable to students of today. One example of each:

When we were on our first field campaign for my diploma thesis, Sepp accompanied me on our boat at Lake Chiemsee hauling some corers for sediment samples on a beautiful and warm day of spring. Everything was great: the wheather, the sampling site and landscape, and in the background the gorgious scenery of the nearer mountains of the Alps. We all were really impressed by this paradise-like surrounding, and when we thankfully realized and expressed this with words at the same moment, he concluded: „Really, you should pay an extra charge to be allowed to do this work here."

The other story happened even earlier, when we were on excursion to study aquatic invertebrates in a student's course. The whether was cold and rainy, and none of us were very motivated to stay 
longer in the nature. We'd rather go home and study the animals collected the day before or alcohol-preserved material in the warm lab. In this moment, when he noticed our severe decline in motivation, Sepp started to tell stories of tough excursion conditions from times when he was a student and a young researcher. During one cold excursion they were happy to find a (cold) spring, in which they were able to warm up their hands... However, Sepp overestimated the pedagogical use of his description. We weren't just impressed, but also shivered, and not convinced to get a grip on ourselves.

In his job, Sepp had only very restricted time or space for personal things. For us as students and a very long time after the examinations, he was „Professor Fittkau“ or simply „Fittkau“. But later, he dearly tried to compensate for this and realized that he had neglected something which should be brought in order. One of the nicest moments for me was - I think it was at his $70^{\text {th }}$ birthday party taking place at the Zoologische Staatssammlung Munich -, when he came to me (and others), at a certain time, clapped friendly on my shoulder, and declared with a bright and very happy smile: „I told the others [i.e. students, and perhaps some staff from the museum], that I am ,Sepp" ". That came deeply from his heart and showed his sense of responsibility for a familiar atmosphere. This was greatly appreciated.

\section{References}

${ }^{1}$ Spies, M. 2002. Professor Ernst Josef Fittkau 75 years, 50 years for chironomid research. - Chironomus Newsletter on Chironomidae Research 15: 2-13.

${ }^{2}$ Sanseverino, A., Stur, E., Wagensonner, I., Gerber, J., Messias, M.C., Spies, M., Reiff, N., Ospina Torres, R., Wiedenbrug, S., Ekrem, T., Riss, W. 2007. Sepp has turned 80. - Chironomus Newsletter on Chironomidae Research 20: 7-8.

${ }^{3}$ Gerstmeier, R. 2001. Laudatio für Herrn Prof. Dr. Ernst Josef Fittkkau. - Mitteilungen der Deutsche Gesellschaft für allgemeine und angewandte Entomolgie 13: 15-18.

${ }^{4}$ Anonymous 1992. Prof. Dr. Ernst Josef Fittkau - sein Leben und Werk. - Spixiana Supplement 17: 7-23.

${ }^{5}$ Fittkau, E. J. 2001. Dankesworte anlässlich der Verleihung der Meigen-Medaille. - Mitteilungen der Deutsche Gesellschaft für allgemeine und angewandte Entomolgie 13: 20. 